\title{
Fomento a la cultura del emprendimiento jurídico: papel fundamental de las universidades en el posconflicto
}

\author{
Martha Lucía Paredes-Bustamante
}

Especialista en Derecho Procesal Penal, Universidad Cooperativa de Colombia. Magíster (c) en Educación con profundización en Investigación. Correo electrónico:

marta.paredesb@campusucc.edu.co

Recibido: 20 de febrero del 2017 Aprobado: 4 de abril del 2017

Cómo citar este artículo: Martha Lucía Paredes-Bustamante. Fomento a la cultura del emprendimiento jurídico: papel fundamental de las universidades en el posconflicto. DIXI 26. Mayo 2017. Pág. 99. doi: http://dx.doi.org/10.16925/di.v19i26.1954

\section{Resumen}

Introducción: en las dinámicas de globalización del mundo contemporáneo y con el panorama que presenta la actual realidad colombiana con los diálogos de paz, de llegar a un acuerdo para terminar el conflicto de más de 50 años y el posterior posconflicto, se plantean amplias exigencias a las universidades, sus directivos, docentes y egresados, con el propósito de desplegar y proyectar una serie de programas y acciones que vinculen a las instituciones de educación superior con las problemáticas del mundo social y productivo desde dimensiones poco exploradas, como, por ejemplo, el emprendimiento para el mundo del derecho. Metodología: el proyecto indaga sobre nuevas posibilidades para practicar el derecho y formar abogados que apliquen el saber jurídico al detectar oportunidades a fin de diseñar propuestas de solución a problemas de contextos con precarios índices de desempleo, salud, educación y convivencia en contextos conflictivos. Resultados y conclusiones: esta exploración sobre aplicaciones novedosas del conocimiento jurídico permitirá establecer si el docente y el estudiante de derecho pueden caminar por campos poco explorados, en este caso, sobre práxis profesionales de un comportamiento emprendedor, mediante la formulación de una idea que pueda ser traducida en proyectos innovadores, cumplir con los valores éticos y los principios constitucionales en contextos de paz y en contextos conflictivos, así como asumir el compromiso y el comportamiento histórico de un abogado gestor requerido por el siglo XxI, el cual se oriente a "saber de derecho y hacia un nuevo saber hacer con el saber de derecho".

Palabras clave: contextos conflictivos, cultura, emprendimiento jurídico, posconflicto. 


\title{
Promoting the Culture of Legal Entrepreneurship: The Fundamental Role of Universities in the Post-conflict Phase
}

\begin{abstract}
Introduction: The dynamics of globalization in the contemporary world and the outlook of the current Colombian reality-the peace dialogs, reaching an agreement to end an over-50-year conflict, and the subsequent post-conflict phase-demand that universities, their managers, professors, and graduates deploy and plan a series of programs and actions to bind higher education institutions to social and labor problems from little-explored dimensions, such as legal entrepreneurship. Methods: The project explores new possibilities to practice law and train lawyers to apply their legal knowledge in detecting opportunities to design solutions to problems in contexts of conflict with precarious rates of unemployment, health, education, and coexistence. Results and conclusions: This exploration on novel applications of legal knowledge will allow to establish whether the law professor and student can walk through little-explored fields-professional practices of an entrepreneurial behavior, in this case-, by formulating an idea that can be translated into innovative projects; comply with ethical values and constitutional principles in contexts of peace and conflict; and take on the commitment and historical behavior of a managing lawyer required by the $21^{\text {st }}$ century, who is oriented to "know law and towards a new know-how with the knowledge of law."
\end{abstract}

Keywords: contexts of conflict, culture, legal entrepreneurship, post-conflict.

\section{Fomento à cultura do empreendimento jurídico: papel fundamental das universidades no pós-conflito}

\section{Resumo}

Introdução: nas dinâmicas de globalização do mundo contemporâneo e com o panorama que a atual realidade colombiana apresenta com os diálogos de paz, se se chegar a um acordo para acabar com o conflito de mais de 50 anos e, em consequência, ao pós-conflito, propõem-se amplas exigências às universidades, conselhos diretivos, docentes e formandos, a fim de desenvolver e projetar uma série de programas e ações que vinculem as instituições de educação superior com as problemáticas do mundo social e produtivo sob dimensões pouco exploradas, como o empreendimento para o mundo do direito. Metodologia: este projeto questiona sobre novas possibilidades para praticar o direito e formar advogados que apliquem o saber jurídico ao detectar oportunidades a fim de elaborar propostas de solução de problemas de cenários com precários índices de desemprego, saúde, educação e convivência em contextos de conflito. Resultados e conclusões: esta exploração sobre novas aplicações do conhecimento jurídico permitirá estabelecer se o docente e o estudante de direito podem caminhar por campos pouco explorados; nesse caso, sobre práxis profissionais de um comportamento empreendedor, mediante a formulação de uma ideia que possa ser traduzida em projetos inovadores, cumprir com os valores éticos e com os princípios constitucionais em contextos de paz e em de conflito, bem como assumir o compromisso e o comportamento histórico de um advogado gestor requerido pelo século xxI, o qual se oriente a "saber de direito e rumo a um novo saber fazer com o saber de direito".

Palavras-chave: contextos conflitivos, cultura, empreendimento jurídico, pós-conflito. 


\section{INTRODUCCIÓN}

La alta tasa de desempleo en Colombia, a pesar de los índices de disminución que en los últimos años viene presentando el Gobierno, la situación de conflicto social y de conflicto armado, el alto número de desplazados por la violencia de los grupos armados y la situación económica exigen de la academia respuestas inmediatas para posibles soluciones que sean viables. Además de la terminación de los diálogos de paz en la Habana entre el Gobierno nacional y la guerrilla de las FARC y la firma de los acuerdos, se espera un posconflicto que requerirá programas específicos que den respuesta ocupacional y de autogestión a los integrantes de estos grupos que se desmovilicen.

En el departamento del Cauca, como uno de los más afectados por el conflicto armado en Colombia y según el informe presentado por la Unidad de Víctimas de Popayán en el 2012, a diferencia de otros departamentos, los hechos tienen una importante especificidad geográfica a nivel de los municipios, en la medida en que los principales lugares de ocurrencia cambian entre los diferentes tipos de hechos victimizantes. Así, se encuentra que Santander de Quilichao es el primer municipio en el total de víctimas y en víctimas de homicidio, con el 8,9\% de estas, y el segundo en víctimas de secuestro, con el 11,1 \%; Popayán tiene la mayor cantidad de victimizaciones en delitos contra la libertad y la integridad sexual (14 \%), desaparición forzada (18,3\%), secuestro $(18,8 \%)$ y tortura (9,3\%); Patía (el Bordo) ocupa el primer lugar en reclutamiento ilegal de niños, niñas y adolescentes, con el $12 \%$ de las víctimas, y el segundo lugar en delitos contra la libertad y la integridad sexual, junto con Argelia y el Tambo; Toribio, por su parte, es el principal municipio en lesiones personales con el 19,9\% de las víctimas sin incapacidades permanentes, y el $14,1 \%$ de las víctimas con este tipo de incapacidades. ${ }^{1}$

Las víctimas del conflicto armado determinan el eje central de los acuerdos de paz, pues, al buscar la verdad, la justicia, la reparación y no repetición, se pretende el restablecimiento de derechos. A la fecha, en Colombia, existen 8131269 víctimas registradas, según datos de la Unidad de Víctimas, creada por el Gobierno Nacional para el registro y trámite de los beneficios que, según la Ley 1448 de 2011, requieren para la mitigación de los daños que ha dejado en ellos el conflicto armado en Colombia. El Cauca reporta

1. Véase Unidad para la Atención y Reparación Integral a las Víctimas. CAUCA: INFORME DEPARTAMENTAL DE HECHOS VICTIMIZANTES A 2012. Disponible en https://rni.unidadvictimas.gov.co/ sites/default/files/ Documentos/ Cauca.pdf en este registro 79813 víctimas del conflicto armado, quienes requieren de atención prioritaria para iniciar la ruta de atención y así gozar de los beneficios de la ley que se sancionó con el objetivo de:

ARTÍCULO $1^{\circ}$. OBJETO. La presente ley tiene por objeto establecer un conjunto de medidas judiciales, administrativas, sociales y económicas, individuales y colectivas, en beneficio de las víctimas de las violaciones contempladas en el artículo $3^{\circ}$ de la presente ley, dentro de un marco de justicia transicional, que posibiliten hacer efectivo el goce de sus derechos a la verdad, la justicia y la reparación con garantía de no repetición, de modo que se reconozca su condición de víctimas y se dignifique a través de la materialización de sus derechos constitucionales. ${ }^{2}$

Con este panorama, es de prever que, con la firma de los acuerdos de paz, las universidades son actores importantes en los territorios de mayor afectación del conflicto armado con sus propuestas de emprendimiento e innovación, tanto económica, como social y jurídica, lo cual permita contribuir en la formación de las víctimas a quienes les serán entregados los recursos a fin de ser reparados por los hechos victimizantes y propender a que los hechos causantes del fraccionamiento social no vuelvan a repetirse. Sin embargo, para que los procesos de reparación social y económica se generen, también se requieren de normas que atiendan las nuevas dinámicas de la economía del sector, así como los nuevos procesos y conflictos sociales que se avecinan ante las nuevas dinámicas sociales que plantea el posconflicto.

Cuando se habla de emprendimiento, se tiene un imaginario económico y de negocios, que es el contexto del que ha surgido, crecido e impulsado con notoriedad, con procesos de creación o innovación de empresas pequeñas y medianas, en la creación y aplicación de tecnologías de última generación para hacer más eficaz la producción de bienes y servicios. Este imaginario colectivo se alimenta del tratamiento de dependencias del Estado y de organizaciones privadas que hacen parecer, así concebido, que el emprendimiento no tendría cabida en disciplinas y ciencias diferentes a las que están en relación permanente con la productividad y la economía. Un ejemplo de esta forma de pensar y hacer emprendimiento se observa en el trabajo de Gómez y Mitchell:

2. Véase Ley 1448 de 2011. Por la cual se dictan medidas de atención, asistencia y reparación integral a las víctimas del conflicto armado interno y se dictan otras disposiciones. Junio 10 del 2011. Do 48096. 
Propuesta 12: Apoyar los procesos de maduración de los emprendimientos de alto valor agregado, y establecer un entorno propicio para el emprendimiento dinámico.

El proceso de creación de empresas sostenibles y que aporten al proceso de integración del país a la economía mundial requiere de una política de acompañamiento y estímulos inexistente en el país. (Página 48) 6. Algunas consideraciones adicionales

Una adecuada promoción de la innovación y el emprendimiento dinámico dependen, no solo de estrategias directas y focalizadas, sino también de medidas indirectas que mejoren el entorno de negocios. Así como la ciencia y la tecnología dependen de la innovación, la innovación depende, a su vez, de un adecuado funcionamiento de los mercados y de unas capacidades gerenciales que permitan introducir y posicionar con éxito bienes y servicios nuevos.

En otras palabras, el desarrollo exitoso de un emprendimiento innovador depende del entorno de competitividad en que se rodee. Se requiere, en este sentido, unas condiciones de competencia libres y justas, bajos costos de producción, alta apropiabilidad de las inversiones, unos mercados abiertos a la competencia internacional, seguridad física y jurídica, tramitología simple y expedita, entre otros. ${ }^{3}$

Sin embargo, la Ley 1014 de $2006,{ }^{4}$ cuando se refiere al fomento a la cultura del emprendimiento, si bien mantiene enmarcado el énfasis en lo económico-empresarial, también abre puertas a la experiencia cotidiana y a las necesidades que el mundo globalizado e intercomunicado de hoy plantean a los profesionales de todas las áreas y a las personas en general, al proponer que el espíritu emprendedor sea tema de formación en Colombia durante todo el proceso educativo, desde la primera infancia hasta la universidad, y al visionar al emprendimiento como una actividad que se despliega por todas las actividades humanas, aun por las más tradicionales e insospechadas. Además, la condición misma del ser humano, siempre curioso, inventivo y transformador, así lo demuestran.

Asimismo, al establecer el emprendimiento como un proceso educativo obligatorio para crear hábitos y acciones culturales de iniciativas con el

\footnotetext{
3. Véase Hernando J. Gómez y Daniel Mitchell. Innovación y emprendimiento en Colombia: balance, perspectivas y recomendaciones de política, 2014-2018. Cuadernos de Fedesarrollo 50. 2014. Pág. 48.

4. Véase Ley 1014 de 2006. De fomento a la cultura del emprendimiento. Enero 27 del 2006. Do 46164.
}

objetivo de innovar desde la primera infancia hasta llegar a la educación superior, en su Artículo 16, permiten que, en las instituciones de educación superior, los estudiantes puedan tener entre sus opciones el presentar proyectos de emprendimiento, al optar por su título de grado profesional. No obstante, la ley deja a la autonomía universitaria (Artículo 69 de la Constitución Política de Colombia de 1991), ${ }^{5}$ la capacidad de hacer sus planes y proyectos educativos, dentro de la libertad de cátedra y de acuerdo con la especificidad de cada carrera profesional.

La ciencia del derecho, enfocada en las formalidades propias de la ley, de los procedimientos judiciales y de los textos de derecho, con apertura reciente a estudios sociojurídicos, no se ha dirigido al emprendimiento en forma expresa y directa, de manera que explore las posibilidades de aplicación del conocimiento jurídico en campos diferentes a la iniciativa empresarial de perspectiva económica, ejecutada por egresados y por profesionales que han decidido iniciar negocios propios relacionados con lo jurídico, o al emplear lo jurídico para apoyar otras actividades productivas.

Por esto, al proponer el emprendimiento jurídico como un proyecto de investigación, en la Facultad de Derecho de la Universidad Cooperativa de Colombia, sede Popayán, se asume el desafío de indagar cómo sería posible formar un abogado emprendedor siguiendo los lineamientos constitucionales de la Ley 1014, y los lineamientos institucionales de la Universidad Cooperativa de Colombia, sede Popayán, de manera tal que se aplique el conocimiento del derecho para la formulación de proyectos de emprendimiento jurídico, no solo en el plano de los negocios y del apoyo o asesorías a actividades productivas, sino al explorar posibilidades emprendedoras en todo el espectro del mundo jurídico, desde el ético, el ambiental, el educativo, el legislativo y el comunitario, entre otros.

La posibilidad se establece desde la búsqueda de un emprendimiento de tipo interdisciplinario y transdisciplinario entre el derecho y ciencias tales como la economía, la administración, las ingenierías, la psicología, la pedagogía, las ciencias de la salud y la contaduría, entre otras. Esto, al trascender la perspectiva exclusiva de la producción de bienes y servicios, a fin de explorar y repensar el emprendimiento desde su planeación, organización y ejecución de proyectos, en el que se integren los conocimientos jurídicos con conocimientos de estas disciplinas, a partir de

\footnotetext{
5. Véase Constitución Política de Colombia [Const]. Art. 69. Julio 7 de 1991 (Colombia).
} 
identificar problemas del entorno y plantearle soluciones en ámbitos tales como el comunitario o el académico, el empresarial, el político, el de gestión y el de autogestión individual y social.

La formación para el emprendimiento tiene como base la solución de problemas reales de la sociedad; por tanto, el proyecto realizó un ejercicio que se inició en los salones con miras a identificar problemas y oportunidades de innovación desde la perspectiva jurídica, y con creatividad para proyectarse sobre la realidad en distintos sectores de la población o en comunidades en particular.

La situación del país, con altos índices de desempleo, amerita que las instituciones de educación superior se comprometan en la búsqueda de alternativas de solución. Una es el fomento del emprendimiento como cultura, como opción de vida y como opción profesional que aporta sus iniciativas en el propósito de contribuir al progreso, al desarrollo y al bienestar, así como a aumentar la calidad de vida de los ciudadanos como sujetos activos en la construcción de su propio destino, tanto de la sociedad payanesa, como de la sociedad caucana.

La decidida participación de los estudiantes, con su capacidad para identificar problemas y formular soluciones, en un contexto histórico, social, económico y cultural, es esencial a fin de proponer una idea emprendedora, ya que la actitud emprendedora se despierta o se nutre según cada caso particular con la sensibilidad y el tacto de cada estudiante-emprendedor, de acuerdo con las necesidades del medio.

El enfoque educativo del emprendimiento como política institucional de la Universidad Cooperativa de Colombia, requiere que el estudiante tenga un espacio para expresar y potencializar su creatividad, por medio de un trabajo que tiene como base la metodología de proyectos, apoyado con bases teóricas y en la didáctica del trabajo colaborativo.

El colombiano es emprendedor por necesidad y por espíritu, es una actitud que se aprecia en el día a día en todas las regiones del país con el denominado "rebusque", practicado por personas que, al estar desempleadas y sin recursos económicos para su manutención, es decir, no empleadas por el sistema económico, idean y establecen pequeños negocios de subsistencia sin estudios, ni proyectos, o capital de inicio, tan solo con las ganas y con la urgencia de no dejarse morir de hambre junto a sus familias, de modo que se convierten en emprendedores informales $y$, de paso, se ubican dentro de la economía informal. Esta situación y actitud emprendedora del ciudadano colombiano debe $-\mathrm{y}$ puede - reorientarse hacia la formalidad, en la que la universidad, junto con instituciones públicas y privadas, tienen mucho por hacer.

\section{MetodologíA}

Esta es fundamentalmente una investigación cualitativa, de tipo explorativo, en la cual la propia observación y el testimonio de los docentes sobre sus resultados del proceso de enseñanza-aprendizaje, se orientan a despertar iniciativas de innovación en el estudiante durante las actividades en el aula de clase y fuera de ella. Requiere recoger experiencias de iniciativas de estudiantes y la observación no estructurada del medio local y departamental, y conduce, desde la perspectiva de la exploración de oportunidades detectadas en las necesidades del medio con la mirada y los conocimientos jurídicos, tanto de docentes, como de los estudiantes de derecho, a una visión de la educación con la cual — con el saber jurídico-, se construyan proyectos emprendedores, en los que se apliquen las habilidades y los conocimientos adquiridos en el salón de clase en dimensión transdisciplinaria. Esto a partir de la observación y el análisis inductivo de experiencias pedagógicas en las diferentes áreas del derecho que se puedan identificar como oportunidades de emprendimientos.

Con el fin de extraer posibilidades concretas de emprendimiento a partir de la praxis educativa realizada por los docentes del programa, se hace necesaria la observación de prácticas docentes y actividades de los estudiantes a partir de lo orientado por los profesores, junto con la interacción dialógica con los docentes que tienen a su cargo las materias y las actividades formativas. Así, en relación directa con los programas, permitirán recoger datos sobre experiencias pedagógicas de clases de las diferentes áreas del derecho en la Universidad Cooperativa de Colombia, sede Popayán.

Para realizar tal interacción, se recurrió a aplicar encuestas a docentes y también a entrevistas, así como al trabajo articulado con las diferentes materias del pénsum académico vigente.

El análisis de los planes (microcurrículos) y de acciones pedagógicas de clases permite recoger experiencias educativas y formativas de la facultad, con miras a establecer cuáles de ellas son en teoría susceptibles de ser llevadas y convertidas en iniciativas de emprendimiento jurídico que ayuden al desarrollo social y a programas del posconflicto.

La observación directa e indirecta del entorno social, político, económico, laboral, educativo, ecológico y familiar complementan metodológicamente lo 
anterior, lo cual permitirá a los profesores y estudiantes de derecho apreciar oportunidades de emprendimiento desde el ámbito jurídico, mediante una guía específica establecida desde el proyecto.

El ejercicio lógico de integración de conocimientos jurídicos con saberes de otras ciencias y disciplinas, posibilita construir y proponer proyectos y planes de emprendimiento en los que el conocimiento jurídico sea un eje articulador o el eje articulador de acciones que conduzcan a concretar el propósito de construir planes de emprendimiento de beneficio común e individual.

Lecturas, charlas y el análisis de literatura y material impreso y digital sobre emprendimiento permitirán reconocer y asumir los conceptos, la filosofía y las prácticas propias del emprendimiento, a fin de aplicarlos en propuestas de proyectos y acciones alternativas que abran nuevas posibilidades a su desempeño profesional y las integre como parte de su proyecto de vida como abogado del presente siglo.

Es fundamental el trabajo con la metodología por proyectos que se orienta al desarrollo de competencias emprendedoras, las cuales permiten al estudiante "saber de derecho y nuevo saber hacer con el saber de derecho".

Se realizarán actividades con las cuales se construyan individual y colectivamente planes y proyectos en los que se materialicen la "formulación" de productos con los cuales integrar saberes previos de derecho e intereses particulares, asociados a desempeños futuros y a la solución de problemáticas reales del contexto en que se vive.

\section{EL EMPRENDIMIENTO JURÍDICO}

Este proyecto se dirige al emprendimiento como actividad formal, la cual se orienta a apoyar actividades de la economía informal, así como a acciones comunitarias e individuales de ciudadanos que requieren apoyo jurídico y directrices que se les puedan aportar desde el derecho, presentados por iniciativas de estudiantes y docentes en contextos socio-educativos, pues articula educación universitaria desde la Facultad de Derecho, con necesidades de las personas del contexto de la ciudad y de un departamento como el Cauca. Tal formalidad del proyecto que se presenta está delineada y soportada en mandatos constitucionales colombianos, como, por ejemplo, el Artículo 38 sobre libertad de asociación, así como en el Artículo 33 sobre libertad económica, y en la Ley 1014 de
2006 de fomento a la cultura del emprendimiento. ${ }^{6}$ Asimismo, una serie de leyes que complementan y apoyan esta actividad, como:

- La Ley 344 de 1996, que contiene normas correspondientes a la creación de empresas. En el Artículo 16, trata sobre el acceso a los recursos para proyectos de incubadoras asociadas al Sena.

- La Ley 550 de 1999, por la cual se establece un régimen que promueva y facilite la reactivación empresarial, la reestructuración de los entes territoriales para asegurar la función social de las empresas, lograr el desarrollo armónico de las regiones y se dictan disposiciones para armonizar el régimen legal vigente con las normas de esta ley.

- La Ley 789 de 2002, dirigida a regular lo referente al apoyo al empleo y a ampliar la protección social, y por la cual se modifican algunos artículos del Código Sustantivo del Trabajo (en el Artículo 40 creó el Fondo Emprender FE, como una cuenta independiente y especial adscrita al Servicio Nacional de Aprendizaje, Sena).

- El Decreto 934 de 2003, el cual reglamenta el funcionamiento del Fondo Emprender. Los artículos del Código Sustantivo del Trabajo (en el Artículo 40 creó el Fondo Emprender FE).

Es así como todo el emprendimiento del que se escuchó hablar y que se vio realizar durante los primeros años de vigencia de la Ley 1014 de 2006 fue de carácter económico-empresarial y aún predomina en el contexto educativo, reforzada por publicaciones de libros y guías de ministerios del Gobierno colombiano, tales como las orientaciones del Ministerio de Educación Nacional:

La cultura del emprendimiento se fomenta de manera gradual: en los niveles de preescolar, básica, y media a partir de las competencias básicas y ciudadanas, se trabajan los procesos nocionales y elementales del emprendimiento; y en la educación media se consolidan las actitudes y conocimientos básicos, para la empresarialidad. Esta se constituye en oportunidad para que el estudiante materialice sus actitudes emprendedoras y para la empresarialidad en el desarrollo de actividades y proyectos orientados a la creación

\footnotetext{
6. Véase Ministerio de la Protección Social. Guía nacional y Regional del Emprendimiento. Disponible en https://www. minsalud.gov.co/trabajoEmpleo/Paginas/emprendimiento.aspx

7. E. g. Ministerio de Educación Nacional. La CUltura DEL EMPRENDIMIENTO EN LOS ESTABLECIMIENTOS EDUCATIVOS Orientaciones generales. Pág. 10. Disponible en https://www. mineducacion.gov.co/ 1759/articles-287822_archivo_pdf.pdf
} 
de empresa con perspectiva de desarrollo sostenible con productividad económica, cultural, científica, tecnológica, deportiva o artística, entre otras.

Esta concepción económica del emprendimiento también se aprecia en la tabla 1 de referencias de algunas universidades colombianas y del sur-occidente, entre ellas las de Popayán, las cuales se revisan a continuación. Solo después se empezó a hacer referencia a otra posibilidad del emprendimiento, atribuyéndole un matiz más humanista bajo la denominación de "emprendimiento social", y el de "emprendimientos culturales": "El espíritu social traspasa el interés de la producción de ganancia económica para llegar hasta las osc. Este es el fin de las empresas u Organizaciones de la Sociedad Civil (osc), en procura de atender necesidades de las comunidades".

En este sentido, el emprendimiento jurídico es un emprendimiento social; sin embargo, lo rebaza en cuanto el jurídico tiene posibilidades de ir más allá y atender a la naturaleza epistémica e integral del derecho, lo que le permite delinear, a partir de todas sus áreas (constitucional, administrativo, civil, laboral, comercial, ambiental y procedimental), amplias posibilidades para un emprendimiento desde el conocimiento jurídico, en los términos conceptuales y prácticos que visualiza este proyecto de investigación. De esta manera, se evidencia que hay más actitudes y oportunidades emprendedoras que las predominantes económica, empresarial y de negocios.

Es importante también hacer referencia a la compleja naturaleza estructural epistémica del derecho, la cual se despliega en una red de interacciones que involucra varias lógicas y factores teórico-prácticos, que van desde su origen histórico-cultural que incluye lo simbólico, el querer y la visión de los pueblos-, pasa por la interpretación hermenéutica de textos jurídicos y de realidades socio-culturales, hasta llegar a su aplicación en el momento de decidir sobre los casos en que se le presentan para darles decisión judicial. Esto enmarcado por el factor político-ideológico, el cual le es consustancial a su estructura y conformación, factores que hacen al derecho diferente a las demás disciplinas y profesiones en las que se aplica el emprendimiento.

Es esta particularidad precisamente la que permite realizar exploraciones que puedan dar cuenta de novedosas posibilidades para el emprendimiento en el contexto de lo jurídico.

Se deduce de las 15 ies citadas en las tablas (tres nacionales, 10 del sur-occidente de Colombia y dos de Popayán) que predomina la filosofía del emprendimiento desde lo económico-empresarial. Sin embargo, se encuentran algunas universidades que, apoyándose en el Artículo 69 de la Constitución Política de 1991, hacen enfoques originales con filosofía propia sobre la formación para el emprendimiento, tales como la Universidad del Cauca, la Universidad Mariana de Nariño o la Universidad de San Buenaventura, seccional Cali, las cuales traspasan el ámbito empresarial y de negocios, para apuntar a uno más social.

Lo anterior es una clara demostración que la formación para el emprendimiento, definitivamente orientada hacia lo económico, a pesar de que se trabaja desde hace algunos años en emprendimientos sociales y culturales, y que se está teorizando con la perspectiva humanística según la cual el emprendimiento es una actividad que se realiza en todas las esferas del ser humano.

Así las cosas, este proyecto tiene ante sí un campo abierto a plenitud para explorar y consolidar emprendimientos desde lo jurídico que traspasen la visión predominantemente económica, dirigiéndose a iniciativas socio-políticas, comunitarias, educativas y ecológicas, así como todas aquellas en las que el conocimiento jurídico sea el eje del emprendedor.

8. Véase Ministerio de Educación Nacional. LA CUltura DEL EMPRENDIMIENTO EN LOS ESTABLECIMIENTOS EDUCATIVOS Orientaciones generales. (2012). Guía N. ${ }^{\circ}$ 39, pág. 10 Disponible en https://www.mineducacion.gov.co/1759/articles287822_archivo_pdf 
Tabla 1. Algunos ejemplos de universidades de Colombia y su filosofía de formación para el emprendimiento

\begin{tabular}{|c|c|c|}
\hline UNIVERSIDAD & FILOSOFÍA FORMATIVA EN EMPRENDIEMIENTO & TENDENCIA \\
\hline $\begin{array}{l}\text { Corporación } \\
\text { Universitaria } \\
\text { Unitec } \\
\text { Papel de las } \\
\text { IES en la } \\
\text { formación de } \\
\text { nuevos emprendedores. } \\
\text { Juan Carlos } \\
\text { Catumba-Arias } \\
\text { Coordinador de } \\
\text { Emprendimiento, } \\
\text { Valores y Liderazgo de } \\
\text { La Corporación } \\
\text { Universitaria Unitec } \\
\text { (2013) }\end{array}$ & $\begin{array}{l}\text { A ocho años haberse sancionado en Colombia la Ley } 1014 \text { de emprendimiento, } \\
\text { en la que se asigna a las instituciones de educación la responsabilidad de } \\
\text { formar competencias emprendedoras en los estudiantes, vale la pena revisar } \\
\text { hasta dónde han llegado las IEs en este propósito. } \\
\text { Con amplia visión, desde hace más de } 20 \text { años, varias IEs colombianas iniciaron } \\
\text { en su interior procesos que generarán inquietudes e iniciativas emprendedo- } \\
\text { ras en su población estudiantil, teniendo incluso que transformar su filosofía } \\
\text { institucional hasta el punto de incorporar en el PEI objetivos orientados hacia el } \\
\text { fortalecimiento de la cultura emprendedora, claramente definidos y expresados } \\
\text { en su misión y visión institucional. } \\
\text { Sin embargo, muchas instituciones de educación superior aún no han dado } \\
\text { el primer paso hacia la estructuración e implementación de estrategias que } \\
\text { permitan al educando fortalecer las competencias para adoptar un estilo de vida } \\
\text { emprendedor. } \\
\text { El asunto va mucho más allá de definir un cargo y nombrar un encargado. Se } \\
\text { requiere, por parte de las directivas de cada institución, una verdadera voluntad } \\
\text { para avanzar hacia la construcción de una sociedad consciente en enfocar sus } \\
\text { esfuerzos y esperanzas en la formación de personas excelentes, capaces de propo- } \\
\text { ner y realizar las grandes y positivas transformaciones que demanda este país. } \\
\text { Voluntad que necesariamente se ve reflejada en la magnitud de recursos asigna- } \\
\text { dos para tal fin. } \\
\text { Por supuesto, debemos reconocer los grandes esfuerzos realizados por aquellas } \\
\text { IEs que han avanzado hacia la construcción de esta nueva sociedad, bien sea } \\
\text { buscando que sus futuros egresados consoliden nuevas empresas, o bien mejoren } \\
\text { las ya existentes. } \\
\text { Véase Juan Carlos Catumba Arias. PApeL DE LAs IEs EN LA FormacióN DE NuE- } \\
\text { vos EmpRENDEDoREs. Corporación Universitaria Unitec. (2013). Disponible en } \\
\text { http://ascun.org.co/media/ attachments/BOLETIN_1.pdf }\end{array}$ & $\begin{array}{l}\text { ECONÓMICA } \\
\text { ANÁLISIS GENERAL } \\
\text { DEL ESTADO DE LA } \\
\text { FORMACIÓN PARA EL } \\
\text { EMPRENDIEMIENTO EN } \\
\text { LAS IES DE COLOM- } \\
\text { BIA HASTA EL 2O13, } \\
\text { INCLUYENDO A TODOS } \\
\text { LOS PROGRAMAS QUE } \\
\text { ESTÁN IMPARTIENDOSE. } \\
\text { (INCLUIDAS FACULTA- } \\
\text { DES DE DERECHO). }\end{array}$ \\
\hline $\begin{array}{l}\text { Universidad Pedagó- } \\
\text { gica y Tecnológica de } \\
\text { Colombia (UPTC) }\end{array}$ & $\begin{array}{l}\text { HACIA UN MODELO DE EMPRENDIMIENTO UNIVERSITARIO. ECONOMÍA. } \\
\text { Este artículo examina algunas de las condiciones más importantes que un } \\
\text { sistema educativo universitario de calidad debe poseer para responder a las } \\
\text { necesidades de la sociedad y a las expectativas de los estudiantes. Para ello, es } \\
\text { importante que la academia esté conectada, tanto con las empresas, como con el } \\
\text { entorno regional. En ese sentido, y dadas las condiciones actuales de la globaliza- } \\
\text { ción, se debe promover en los estudiantes el aprendizaje y la práctica del empren- } \\
\text { dimiento como una actitud que les permita generar una capacidad creativa sobre } \\
\text { el entorno, actuando así como empresarios innovadores, capaces de asumir } \\
\text { riesgos, dar solución a problemas, ser productores de empleo y de riqueza. } \\
\text { Escuela de Economía. } \\
\text { Facultad de Ciencias Económicas y Administrativas. } \\
\text { Universidad Pedagógica y Tecnológica de Colombia. } \\
\text { Dolly Yazmín Camacho Corredor. Hacia un modelo de emprendimiento univer- } \\
\text { sitario. } \\
\text { REvista ApunTEs DEL CENEs XXVII(43). I semestre del } 2007 \text {. Disponible en } \\
\text { http://dialnet.unirioja.es/servlet/articulo?codigo=4829113 }\end{array}$ & $\begin{array}{l}\text { ECONÓMICA. } \\
\text { DIRIGIDO A TODOS LOS } \\
\text { PROGRAMAS Y ESTU- } \\
\text { DIANTES. NO CONTEM- } \\
\text { PLA A LA FACULTAD DE } \\
\text { DERECHO EN PARTI- } \\
\text { CULAR. }\end{array}$ \\
\hline Universidad Nacional & 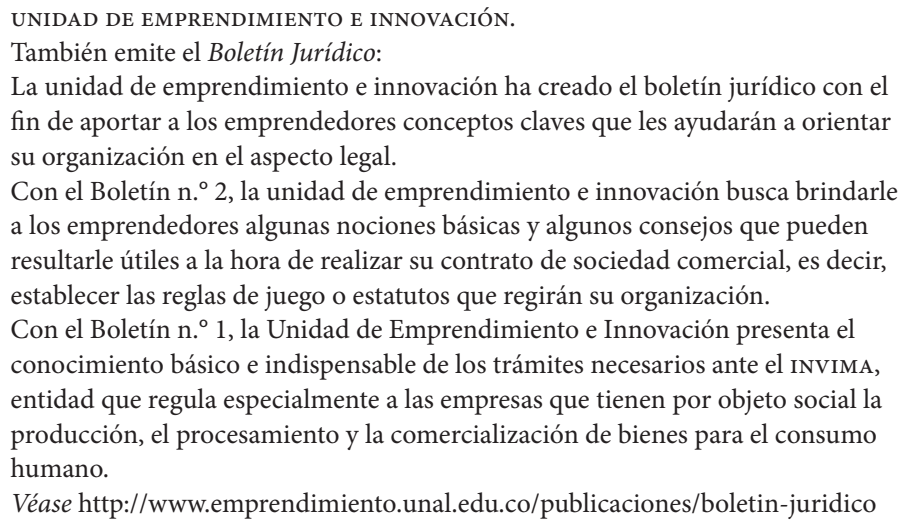 & $\begin{array}{l}\text { ECONÓMICO-ORIEN- } \\
\text { TACIÓN JURÍDICA } \\
\text { EMPRESARIAL } \\
\text { DIRIGIDO A TODOS } \\
\text { LOS ESTUDIANTES. } \\
\text { NO CONTEMPLA A LA } \\
\text { FACULTAD DE DERECHO } \\
\text { EN PARTICULAR. }\end{array}$ \\
\hline
\end{tabular}

Fuente: elaboración propia 
Tabla 2. Emprendimiento en universidades del suroccidente de Colombia

\begin{tabular}{|c|c|c|}
\hline UNIVERSIDAD & FILOSOFÍA FORMATIVA EN EMPRENDIMIENTO & TENDENCIA \\
\hline $\begin{array}{l}\text { Universidad Autónoma } \\
\text { de Occidente } \\
\text { (UAO) }\end{array}$ & 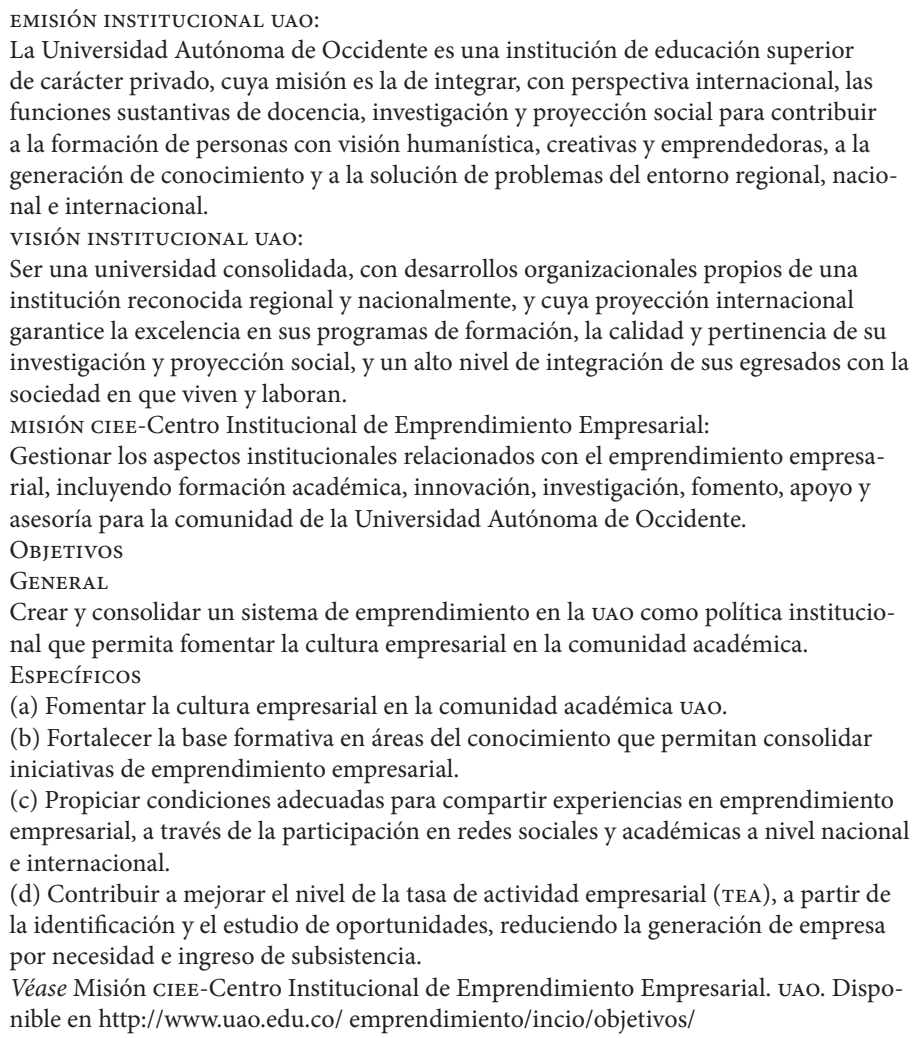 & $\begin{array}{l}\text { ECONÓMICA-EMPRESA- } \\
\text { RIAL } \\
\text { NO POSEE FACULTAD DE } \\
\text { DERECHO. }\end{array}$ \\
\hline $\begin{array}{l}\text { Universidad Javeriana, } \\
\text { Cali }\end{array}$ & $\begin{array}{l}\text { La Oficina de Emprendimiento tiene el gusto de invitar a la Comunidad Javeriana a } \\
\text { participar en las actividades de acompañamiento a emprendedores, correspondientes } \\
\text { al primer periodo del 2015. Profesores, colaboradores, estudiantes y egresados son } \\
\text { bienvenidos en nuestro programa CAMPUs NOVA, el cual fue reconocido por la oEA } \\
\text { como "Modelo de referencia por su aporte al emprendimiento y la innovación". } \\
\text { La Oficina de Emprendimiento está compuesta por tres líneas: Hábitat Emprendedor, } \\
\text { Emprendimiento en Movimiento y Formación Emprendedora, garantizando un pro- } \\
\text { ceso integral en la construcción de nuevas empresas. } \\
\text { En el "Hábitat Emprendedor", se destaca el programa CAMPUs NovA, con un modelo } \\
\text { de acompañamiento constante a emprendedores empresariales, sociales y culturales } \\
\text { a través de tres etapas: Pre-Momentum, Inmersión y Momentum. Entre los aspectos } \\
\text { más relevantes, se encuentran las mentorías con reconocidos empresario s de la región, } \\
\text { el acceso al espacio de coworking entre emprendedores y el acompañamiento para } \\
\text { participar en convocatorias, entre otros. } \\
\text { Dentro del marco de "Emprendimiento en Movimiento", proveemos capacitaciones y } \\
\text { diplomados sobre emprendimiento e innovación a reconocidas empresas de la región } \\
\text { y del país. } \\
\text { Finalmente, estamos comprometidos con la internacionalización de los emprendedo- } \\
\text { res; a través del tercer eje, "Formación Emprendedora", estamos afianzando las rela- } \\
\text { ciones con universidades jesuitas que le apuestan al emprendimiento, entre las que se } \\
\text { destacan Santa Clara University, con su instituto GsBi (Global Social Benefit Institute) } \\
\text { y University of San Francisco. También buscamos proveer las condiciones para que } \\
\text { los estudiantes de últimos semestres puedan hacer sus trabajos de grado y prácticas } \\
\text { profesionales en emprendimiento. } \\
\text { Los nuevos emprendedores pueden participar de nuestras charlas informativas } \\
\text { mensuales o visitarnos en las instalaciones de Campus Nova para conocer más sobre } \\
\text { nuestro programa, actividades y eventos, los cuales son realizados con el propósito de } \\
\text { promover la cultura emprendedora en la universidad. } \\
\text { Véase } \\
\text { Pontificia Universidad Javeriana Cali. Oficina DE EmpRENDImiENTo. Disponible en } \\
\text { http://www.javerianacali.edu.co/conoce-como-se-gesta-el-emprendimiento-javeriano }\end{array}$ & $\begin{array}{l}\text { PEDAGÓGICO-EMPRE- } \\
\text { SARIAL } \\
\text { DIRIGIDO A TODOS } \\
\text { LOS ESTUDIANTES; Y } \\
\text { NO CONTEMPLA A LA } \\
\text { FACULTAD DE DERECHO } \\
\text { EN PARTICULAR. }\end{array}$ \\
\hline
\end{tabular}


(viene)

\begin{tabular}{|c|c|c|}
\hline $\begin{array}{l}\text { Universidad Libre, } \\
\text { Cali }\end{array}$ & $\begin{array}{l}\text { UNIVERSIDAD LIBRE-SECCIONAL CALI } \\
\text { ECONOMÍA (SNIES 54O39), MODALIDAD PRESENCIAL } \\
\text { El egresado del programa de Economía con énfasis en Negocios Internacio- } \\
\text { nales, es un profesional que puede participar en estudios de investigación } \\
\text { económica. } \\
\text { Participar en estudios de investigación económica. } \\
\text { Analizar, interpretar y sugerir alternativas que permitan dar solución a los } \\
\text { problemas socioeconómicos regionales y nacionales. } \\
\text { Potenciar el funcionamiento y los resultados de las organizaciones empre- } \\
\text { sariales, a partir del conocimiento de la actividad productiva en los ámbitos } \\
\text { local, regional e internacional. } \\
\text { Asesorar y realizar consultoría empresarial. } \\
\text { Formular y evaluar proyectos de inversión. } \\
\text { Realizar estudios de análisis financiero y medición de riesgo. } \\
\text { Liderar proyectos de emprendimiento social y empresarial. } \\
\text { Continuar estudios de posgrado en los ámbitos propios de su competencia. } \\
\text { Perfil ocupacional: El egresado del programa de Economía con énfasis en } \\
\text { Negocios Internacionales, es un profesional que puede desempeñarse en: } \\
\text { Cargos de dirección de empresas productoras de bienes y servicios. } \\
\text { Servicios vinculados o no al comercio internacional. } \\
\text { La dirección de proyectos de intervención social. } \\
\text { Actividades investigativas en organizaciones gubernamentales y no guber- } \\
\text { namentales. } \\
\text { Empresas comerciales e industriales del Estado; y departamentos adminis- } \\
\text { trativos y de control estatal. } \\
\text { Véase http://orientacion.universia.net.co/informacion_carreras/pregrado/ } \\
\text { economia-snies-54039-383/universidad-libre---seccional-cali-27.html }\end{array}$ & $\begin{array}{l}\text { ECONÓMICA-EMPRE- } \\
\text { SARIAL-SOCIAL } \\
\text { DIRIGIDO A TODOS } \\
\text { LOS ESTUDIANTES. } \\
\text { NO CONTEMPLA A LA } \\
\text { FACULTAD DE DERE- } \\
\text { CHO EN PARTICULAR. }\end{array}$ \\
\hline $\begin{array}{l}\text { Universidad Santiago } \\
\text { de Cali }\end{array}$ & $\begin{array}{l}\text { PROGRAMA DE FORMACIÓN DE EMPRESARIOS (SNIES 7804) (PRESENCIAL) } \\
\text { El programa tiene como componente fundamental el emprendimiento (plan } \\
\text { de negocios igual a creación de empresas), y como apoyo a la administración } \\
\text { y gestión de las organizaciones económicas y comerciales, y otras áreas tales } \\
\text { como la cuantitativa, informática, humano-social y jurídica. } \\
\text { Perfil Profesional: } \\
\text { El empresario es un profesional emprendedor con alto sentido de inde- } \\
\text { pendencia económica, con competencias en la creatividad, la innovación y } \\
\text { el liderazgo para visualizar permanentemente oportunidades de negocios } \\
\text { competitivos para la empresa y gestar cambios significativos en las organiza- } \\
\text { ciones empresariales y sociales. } \\
\text { Perfil ocupacional: } \\
\text { El egresado de formación de empresarios tiene tres roles principales que } \\
\text { son: papel empresarial, que es la habilidad de detectar las oportunidades de } \\
\text { negocio, movilizar los recursos necesarios para explotarlos y trabajar largas } \\
\text { jornadas; papel gerencial, poseer competencias conceptuales, interperso- } \\
\text { nales y políticas; papel técnico, habilidades necesarias para administrar las } \\
\text { operaciones de la empresa. } \\
\text { Véase Universidad Santiago de Cali. PROGRAMA FormACIóN DE EMPRE- } \\
\text { sARIOs. Disponible en http://orientacion.universia.net.co/informa- } \\
\text { cion_carreras/pregrado/formacion-de-empresarios-snies-7804-1249/ } \\
\text { universidad-santiago-de-cali-38.html }\end{array}$ & $\begin{array}{l}\text { ECONÓMICO-EMPRE- } \\
\text { SARIAL } \\
\text { DIRIGIDO A LOS } \\
\text { ESTUDIANTES DEL } \\
\text { PROGRAMA DE FOR- } \\
\text { MACIÓN DE EMPRESA- } \\
\text { RIOS EN PARTICULAR. } \\
\text { SE EXCLUYE POR } \\
\text { TANTO A LA FACULTAD } \\
\text { DE DERECHO. } \\
\text { LO JURÍDICO APARECE } \\
\text { COMO UN APOYO. }\end{array}$ \\
\hline
\end{tabular}


(viene)

\begin{tabular}{|c|c|c|}
\hline $\begin{array}{l}\text { Universidad de San } \\
\text { Buenaventura, seccio- } \\
\text { nal Cali }\end{array}$ & 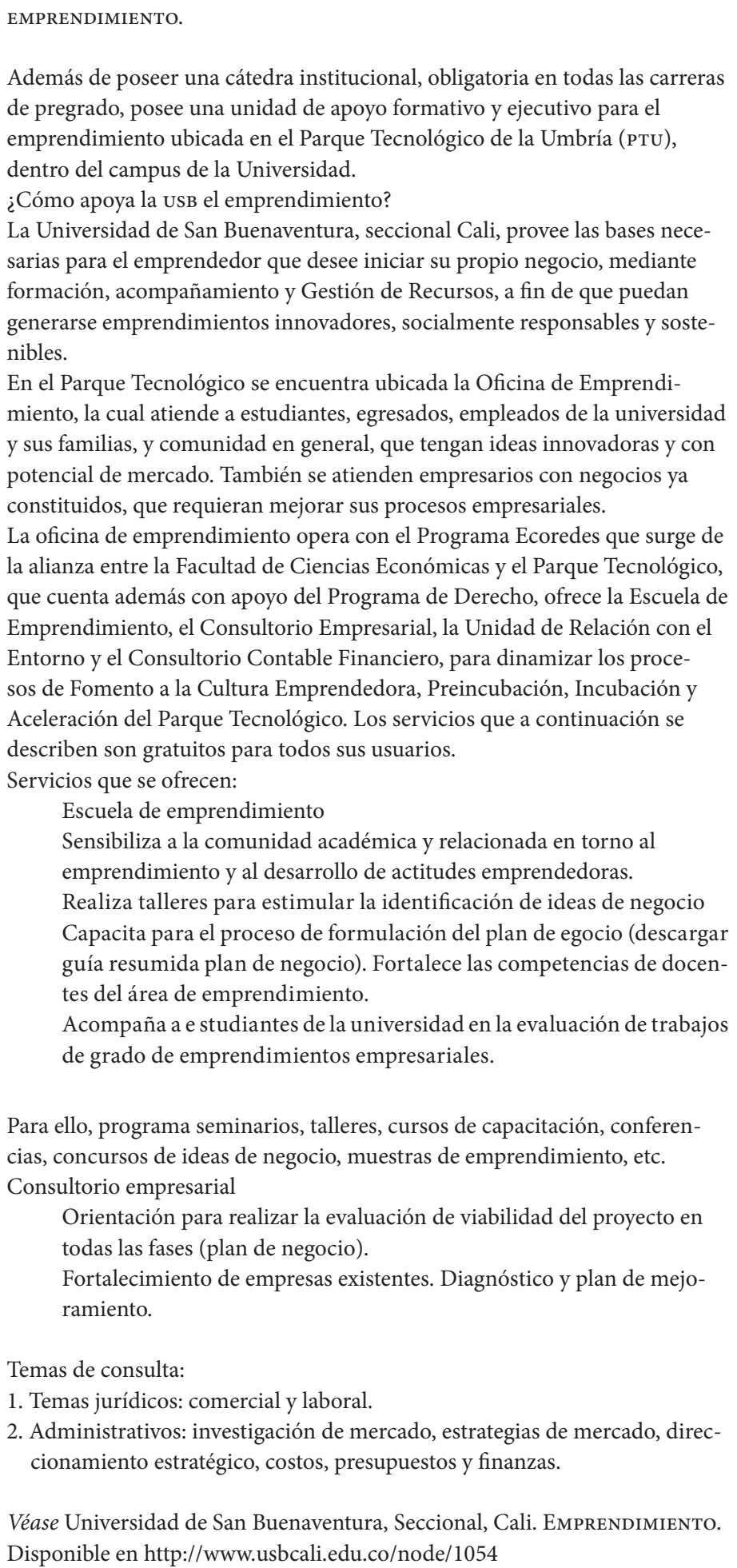 & $\begin{array}{l}\text { ECONÓMICO-EMPRE- } \\
\text { SARIAL Y SOCIAL } \\
\text { INCLUYE A LA FACUL- } \\
\text { TAD DE DERECHO, } \\
\text { COMO UNO DE SUS } \\
\text { APOYOS AL PROCESO } \\
\text { DE ORIENTACIÓN A } \\
\text { EMPRENDEDORES } \\
\text { INTERNOS Y EXTER- } \\
\text { NOS. } \\
\text { ADEMÁS, EN LA FACUL- } \\
\text { TAD DE DERECHO SE } \\
\text { IMPARTE EL CURSO } \\
\text { INSTITUCIONAL OBLI- } \\
\text { GATORIO DE EMPREN- } \\
\text { DIMIENTO DURANTE } \\
\text { UN SEMESTRE, CON } \\
\text { ENFOQUE DESDE EL } \\
\text { DERECHO. } \\
\text { TAMBIÉN EXPRESA } \\
\text { EN SU PÁGINA WEB } \\
\text { QUE LA FORMA- } \\
\text { CIÓN DEL ABOGADO } \\
\text { ESTÁ ORIENTADA AL } \\
\text { EMPRENDIMIENTO. }\end{array}$ \\
\hline
\end{tabular}


(viene)

\begin{tabular}{|c|c|c|}
\hline Universidad del Valle & $\begin{array}{l}\text { Programa institucional de emprendedores. Está adscrito al Programa de } \\
\text { Educación Continua, que hace parte de la Dirección de Extensión y Educación } \\
\text { Continua, la cual se encuentra adscrita a la Vicerrectoría Académica y tiene } \\
\text { la responsabilidad de cumplir con las actividades encomendadas para tal fin. } \\
\text { Ofrece asesoría y gestiona servicios en educación no formal, y en conjunto con } \\
\text { las facultades, institutos académicos y sedes regionales de la universidad, hace } \\
\text { presencia en la región, fortaleciendo la calidad y pertinencia de la formación; y } \\
\text { aunque en su gran mayoría estos programas se ofrecen a estudiantes y egresa- } \\
\text { dos de las instituciones de educación superior, algunos programas son dirigidos } \\
\text { a grupos y comunidades específicos, los cuales deben cumplir con perfiles de } \\
\text { formación, de acuerdo con el nivel y tipo de evento. El Programa Institucional } \\
\text { de Emprendedores se crea con el fin de fortalecer el potencial emprendedor de } \\
\text { los estudiantes de la Universidad del Valle, a través del desarrollo de habilida- } \\
\text { des para concebir, planear y poner en marcha nuevas organizaciones con o sin } \\
\text { ánimo de lucro, de autogestión, colectivo o asociativo. } \\
\text { Véase Universidad del Valle. PROGRAMA INSTITUCIONAL DE EMPRENDEDORES. } \\
\text { Disponible en } \\
\text { http://extension.univalle.edu.co/index.php/emprendedores }\end{array}$ & $\begin{array}{l}\text { GESTIÓN-AUTOGESTIÓN } \\
\text { ORGANIZACIONAL Y } \\
\text { SOCIAL } \\
\text { NO POSEE FACULTAD DE } \\
\text { DERECHO. }\end{array}$ \\
\hline ICESI & $\begin{array}{l}\text { ESPÍRITU EMPRESARIAL ICESI } \\
\text { Desde } 1985 \text { la Universidad ICESI cuenta con el Centro de Desarrollo del Espí- } \\
\text { ritu Empresarial-CDEE, primera unidad académica en Colombia que, a través } \\
\text { de procesos educativos y con la participación permanente de la comunidad } \\
\text { universitaria, propende a la creación, apropiación y difusión de los conoci- } \\
\text { mientos y actividades propias de las áreas de: } \\
\text { - Desarrollo del espíritu y de la cultura empresarial } \\
\text { - Creación de empresas } \\
\text { - Educación empresarial } \\
\text { - Formación de líderes empresariales } \\
\text { El cDEE provee una atmósfera de aprendizaje, de apoyo, de formación, de } \\
\text { motivación y de convicción, que impulsa y da herramientas para la creación de } \\
\text { empresas y la formación de los estudiantes como líderes empresarios. } \\
\text { El CDEE fue premiado en el } 2010 \text { por la us Association for Small Business and } \\
\text { Entrepreneurship usAsBE como el mejor programa de espíritu empresarial } \\
\text { fuera de los Estados Unidos. } \\
\text { Véase http://www.icesi.edu.co/espiritu_empresarial.php } \\
\text { La Facultad de Ciencias Administrativas y Económicas de la Universidad } \\
\text { ICESI, acreditada por la Association to Advance Collegiate Schools of Business } \\
\text { (AACSB), se destaca por su contribución a la formación humana e integral de } \\
\text { personas líderes, innovadoras, emprendedoras, con pensamiento crítico y } \\
\text { estratégico, perspectiva global y poseedoras del conocimiento necesario para } \\
\text { destacarse en el mercado laboral, no solo por sus competencias, sino por su } \\
\text { excelente desempeño profesional en administración, economía, contaduría y } \\
\text { finanzas, negocios internacionales y mercadeo internacional y publicidad. } \\
\text { Los profesionales egresados de los programas de pregrado y posgrado de la } \\
\text { facultad, son capaces de comprender e intervenir adecuadamente en la gestión } \\
\text { organizacional de las empresas y en el desarrollo innovador y sostenible de } \\
\text { estas, hasta en los entornos más complejos. Su saber actualizado y pertinente } \\
\text { les permite servir adecuadamente a las organizaciones, destacándose por su } \\
\text { actuar ético y socialmente responsable y por sus valores de justicia, honestidad, } \\
\text { tolerancia y respeto por los demás y por el ambiente. }\end{array}$ & $\begin{array}{l}\text { ECONÓMICO-EMPRE- } \\
\text { SARIAL } \\
\text { DIRIGIDO A TODOS } \\
\text { LOS ESTUDIANTES, } \\
\text { ESPECIALMENTE A LOS } \\
\text { DE LA FACULTAD DE } \\
\text { CIENCIAS AMINISTRA- } \\
\text { TIVAS Y ECONÓMICAS, } \\
\text { Y NO CONTEMPLA A LA } \\
\text { FACULTAD DE DERECHO } \\
\text { EN PARTICULAR. }\end{array}$ \\
\hline
\end{tabular}

Fuente: elaboración propia 
Tabla 3. Emprendimiento en otras universidades del suroccidente de Colombia

\begin{tabular}{|c|c|c|}
\hline UNIVERSIDAD & FILOSOFÍA FORMATIVA EN EMPRENDIMIENTO & TENDENCIA \\
\hline $\begin{array}{l}\text { Universidad Central } \\
\text { del Valle (UCEVA) }\end{array}$ & 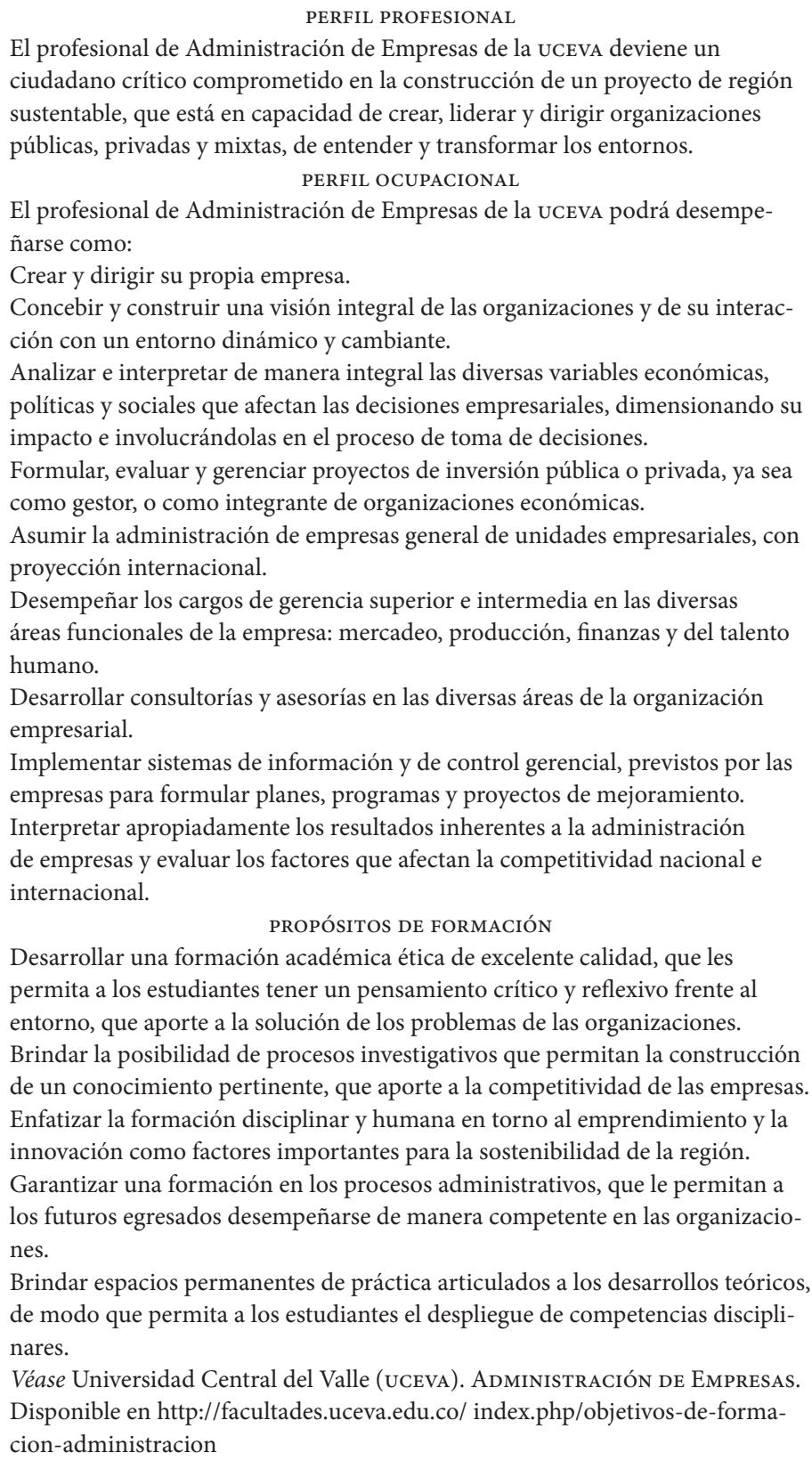 & $\begin{array}{l}\text { ECONÓMICO-EMPRE- } \\
\text { SARIAL } \\
\text { DIRIGIDO A TODOS } \\
\text { LOS ESTUDIANTES. } \\
\text { NO CONTEMPLA A LA } \\
\text { FACULTAD DE DERE- } \\
\text { CHO EN PARTICULAR. }\end{array}$ \\
\hline
\end{tabular}


(viene)

\begin{tabular}{|c|c|c|}
\hline $\begin{array}{l}\text { Universidad Mariana } \\
\text { de Nariño }\end{array}$ & 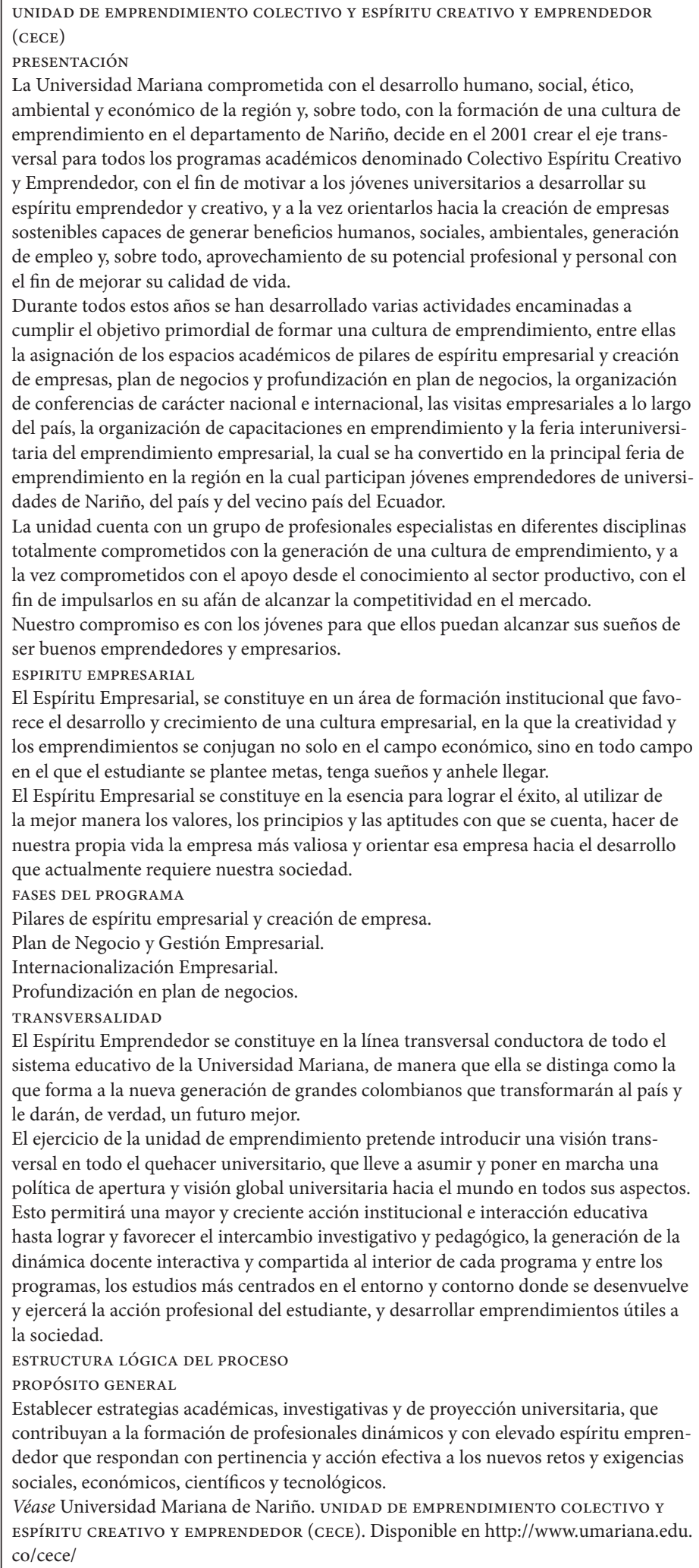 & $\begin{array}{l}\text { ECONÓMICO-EMPRE- } \\
\text { SARIAL } \\
\text { LA FACULTAD DE } \\
\text { DERECHO INCLUYE EL } \\
\text { CURSO DE ESPÍRITU } \\
\text { EMPRENDEDOR EN IV } \\
\text { SEMESTRE. }\end{array}$ \\
\hline
\end{tabular}


(viene)

\begin{tabular}{|c|c|c|}
\hline Universidad de Nariño & $\begin{array}{l}\text { La unidad de emprendimiento de la Universidad de Nariño, invita a la comu- } \\
\text { nidad en general y en especial a los estudiantes de las diferentes universidades } \\
\text { de la región, a conocer cómo se debe iniciar un proyecto empresarial y cómo se } \\
\text { puede acceder al capital semilla, puesto que esta unidad trabaja con el Fondo } \\
\text { Emprender. } \\
\text { Del Fondo Emprender se puede beneficiar todo ciudadano colombiano mayor de } \\
\text { edad con las siguientes características: } \\
\text { Los estudiantes que cursan los dos últimos semestres en cualquier universidad. } \\
\text { Egresados de cualquier universidad que hayan terminado materias en los últimos } \\
12 \text { meses. } \\
\text { Profesional universitario cuyo primer título haya sido obtenido durante los } \\
\text { últimos } 24 \text { meses. } \\
\text { Estudiantes que se encuentren cursando cualquier especialización o maestría, así } \\
\text { como egresados de estos programas dentro de los últimos } 60 \text { meses. } \\
\text { La unidad de emprendimiento de la Universidad de Nariño tiene como objetivo } \\
\text { realizar acompañamiento a los estudiantes del alma mater en la creación del } \\
\text { plan de negocios de la empresa deseada, con el fin de socializarlo con el Fondo } \\
\text { Emprender y acceder al capital semilla. } \\
\text { El Fondo Emprender trabaja con FonADE para administrar los recursos que se } \\
\text { van a asignar de acuerdo con las convocatorias y a los diferentes potenciales } \\
\text { emprendedores de quienes presentan sus planes de negocios. } \\
\text { Véase http://ccomunicaciones.udenar.edu.co/?p=6996 }\end{array}$ & $\begin{array}{l}\text { ECONÓMICO-EMPRE- } \\
\text { SARIAL } \\
\text { DIRIGIDO A TODOS LOS } \\
\text { ESTUDIANTES Y COMU- } \\
\text { NIDAD ESTUDIANTIL } \\
\text { DEL SUROCCIDENTE } \\
\text { COLOMBIANO Y NO } \\
\text { CONTEMPLA A LA } \\
\text { FACULTAD DE DERECHO } \\
\text { EN PARTICULAR. }\end{array}$ \\
\hline
\end{tabular}

Fuente: elaboración propia

Tabla 4. Formación en emprendimiento en dos universidades de Popayán

\begin{tabular}{|c|c|c|}
\hline UNIVERSIDAD & FILOSFÍA FORMATIVA EN EMPRENDIMIENTO & TENDENCIA \\
\hline Universidad del Cauca & $\begin{array}{l}\text { EXISTE EL PROGRAMA "EMPRENDE" } \\
\text { QUIÉNES SOMOS } \\
\text { El programa de emprendimiento de la Universidad del Cauca "Emprende" es una } \\
\text { iniciativa impulsada por el Centro de Estudios y Servicios, cuyo fin es ofrecer un } \\
\text { espacio de encuentro y participación para la comunidad universitaria en temas } \\
\text { relacionados al emprendimiento. Además de crear los vínculos necesarios entre } \\
\text { el Estado, la universidad y el sector productivo, que permitan propiciar nuevas } \\
\text { dinámicas de desarrollo económico y social en la región y en el país. } \\
\text { MisióN } \\
\text { Nuestra misión es propiciar un ambiente de motivación y acompañamiento a los } \\
\text { emprendedores de la comunidad universitaria (estudiantes, egresados, docentes, } \\
\text { funcionarios), con el propósito de convertirlos en gestores de procesos de trans- } \\
\text { formación para el desarrollo de la región y el país. } \\
\text { VISIóN } \\
\text { Ser una universidad líder en emprendimiento universitario con alto impacto } \\
\text { social a nivel nacional e internacional. } \\
\text { OBJETIVos } \\
\text { GENERAL } \\
\text { Contribuir a la formación integral de profesionales con competencias emprende- } \\
\text { doras capaces de liderar procesos de desarrollo. } \\
\text { ESPECíficos } \\
\text { Fomentar una cultura emprendedora en todos los niveles de la institución. } \\
\text { Crear un espacio dentro de la academia que estimule la gestación de ideas de } \\
\text { emprendimiento. } \\
\text { Relacionar el programa "Emprende" con las diferentes instituciones que finan- } \\
\text { cian y promueven el emprendimiento. } \\
\text { Construir un puente de integración entre la universidad y el sector productivo de } \\
\text { la región y el país. } \\
\text { Véase https://emprendimientoces.wordpress.com/about/ }\end{array}$ & $\begin{array}{l}\text { SOCIO-ECONÓMICA } \\
\text { UNIDAD INSTITUCIO- } \\
\text { NAL, QUE INCLUYE A } \\
\text { TODAS LAS CARRERAS, } \\
\text { INCLUIDA DERECHO. }\end{array}$ \\
\hline
\end{tabular}




\begin{tabular}{|c|c|c|}
\hline & 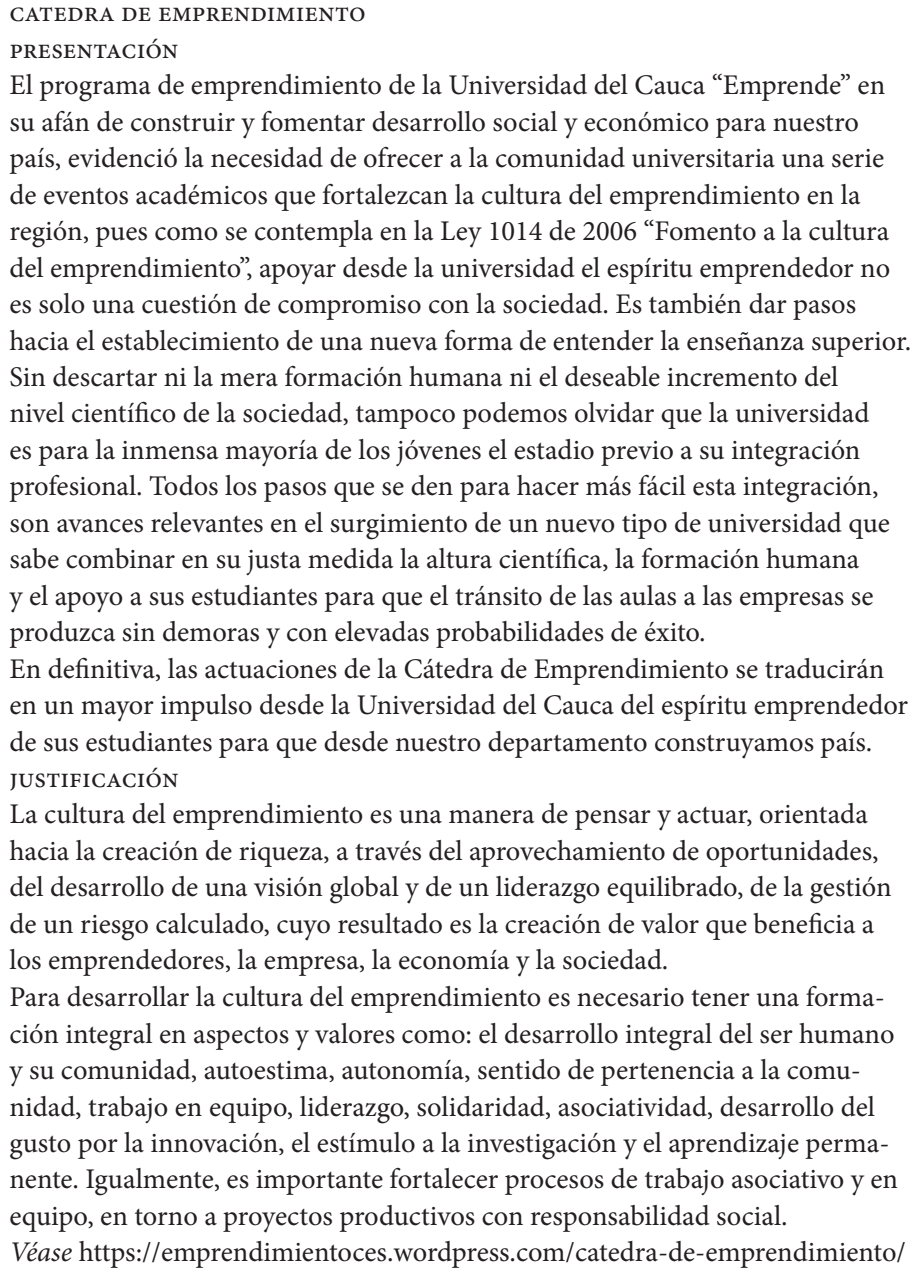 & \\
\hline $\begin{array}{l}\text { Fundación Universita- } \\
\text { ria de Popayán (FUP) }\end{array}$ & $\begin{array}{l}\text { UNIDAD DE EMPRENDIMIENTO UNDEFUP } \\
\text { A través del Acuerdo } 091 \text { del } 18 \text { de Mayo de 2010, el Consejo Académico de la } \\
\text { Fundación Universitaria de Popayán aprobó el proyecto de creación de la Uni- } \\
\text { dad de Emprendimiento de la Fundación Universitaria de Popayán (UNDEFUP). } \\
\text { UNDEFUP es la encargada de fomentar, coadyuvar y encaminar a la comunidad } \\
\text { universitaria en un espíritu emprendedor para consolidar su propio ecosistema } \\
\text { de emprendimiento a través de asesorías, seminarios, talleres, foros, etc. en los } \\
\text { cuales: } \\
\text { Fomentamos el espíritu emprendedor. } \\
\text { Asesoramos tu idea o proyecto. } \\
\text { Recomendamos fuentes de financiación. } \\
\text { Acompañamos el proceso de emprendimiento en todas sus fases. } \\
\text { Informamos sobre convocatorias. } \\
\text { Promovemos el desarrollo empresarial. } \\
\text { Toda la gestión es planeada por la Coordinación de Emprendimiento y su } \\
\text { ejecución y puesta en marcha se realiza con el apoyo de los coordinadores de } \\
\text { emprendimiento de cada uno de los programas académicos. }\end{array}$ & $\begin{array}{l}\text { SOCIO-ECONÓMICA } \\
\text { UNIDAD INSTITUCIO- } \\
\text { NAL, QUE INCLUYE A } \\
\text { TODAS LAS CARRERAS. } \\
\text { INCLUIDA DERECHO. }\end{array}$ \\
\hline
\end{tabular}


(viene)

\begin{tabular}{|c|c|}
\hline & $\begin{array}{l}\text { EMPRENDEDORES FUP } \\
\text { El emprendedor FUP es una persona inquieta, despierta, apasionada, con ganas } \\
\text { de aprender enfocado en el logro, dinámico, luchador, fuerte, que no le teme al } \\
\text { fracaso y que por el contrario aprovecha cada impase para convertirlo en una } \\
\text { fortaleza y así potencializarlo para la consecución de su proyecto; además, cuenta } \\
\text { con características de líder, alta adaptabilidad al entorno, creativo, innovador y } \\
\text { busca marcar una diferencia, siempre buscando el bien común, donde el dinero } \\
\text { es solo la consecuencia de tener un buen producto o servicio. } \\
\text { Soy Emprendedor Fup lo denotamos con un bombillo pues, en la representación } \\
\text { de la IDEA, que en conjunto con las ruedas dentadas, simbolizan el engranaje } \\
\text { del proceso por el cual debe pasarse para lograr materializar esa idea y lograr un } \\
\text { proyecto (empresa o negocio). } \\
\text { Soy Emprendedor FUP es la estrategia comunicacional y de mercadeo creada por } \\
\text { la Unidad de Emprendimiento unDEUFP para fomentar una cultura emprende- } \\
\text { dora, creativa e innovadora, en pro del desarrollo integral del estudiante como } \\
\text { profesional, de la sociedad como aporte laboral y económico y de la región para } \\
\text { la disminución de los índices de desocupación y aumento de la productividad. } \\
\text { ASESORíAs } \\
\text { Brindamos asesoría a los estudiantes y egresados que tienen ideas de negocio, } \\
\text { negocios propios o negocios familiares } \\
\text { Véase http://fup.edu.co/web_2014/emprendimiento/undefup/ }\end{array}$ \\
\hline
\end{tabular}

Fuente: elaboración propia

\section{Conclusiones}

La Universidad Cooperativa de Colombia ha establecido desde la Oficina de Proyección Social el concepto y actividad del emprendimiento solidario. En su página web, se encuentra la información que especifica cómo se aborda la formación para el emprendimiento desde el concepto de "emprendimiento solidario e innovación social", lo cual se desarrolla desde la organización de INDESCO, que es el Instituto de Economía Social y Cooperativismo, el cual desarrolla funciones de investigación, educación y proyección social que permiten generar y desarrollar no solo en el estudiante, sino en los docentes y en el ámbito social de Popayán la cultura de emprendimiento jurídico, con la participación de los estudiantes de derecho con su programa de monitores solidarios. Este se estructura desde el interés de los estudiantes por dar a conocer temas de derecho, tales como la economía solidaria, el cooperativismo, los mecanismos alternativos de solución de conflictos, las formas de asociación, el derecho de alimentos y el procedimiento para su exigibilidad, derechos laborales, derechos de interés general a comunidades vulnerables de la ciudad de Popayán (desplazados, madres cabeza de familia, juntas de acción comunal y cooperativas de trabajo asociado).
Los microcurrículos de los cursos de Sociología Jurídica, Derecho Constitucional e Institucionales I, II Y III, y asignaturas como Proyecto de Investigación, Técnicas de Investigación, además de los semilleros de investigación de Ius Emprender, permiten la participación de los estudiantes en el estudio de la problemática social de Popayán, así como generar propuestas de desarrollo de emprendimiento jurídico y producir posibilidades de soluciones jurídicas para estos, ya que las dinámicas implementadas por los docentes de cada curso le permiten al estudiante conocer de cerca las problemáticas del entorno y plantear soluciones jurídicas desde el aula de clase. Además, se hace parte activa del problema al intentar presentar soluciones según las dinámicas implementadas en cada curso por el docente, como lo hacen en el curso de Proyecto de Investigación, o en los cursos de Derecho Constitucional, en los que aparte del problema, exploran las posibilidades de presentar proyectos de ley frente a los vacíos jurídicos que se presentan en la solución jurídica de problemas sociales identificados por ellos.

Producto de las encuestas aplicadas a docentes y estudiantes de la Facultad de Derecho de la Universidad Cooperativa, sede Popayán, se logra establecer que es necesario motivar el espíritu solidario e investigativo de los estudiantes y docentes de 
la Facultad de Derecho, para así lograr en ellos un espíritu más emprendedor jurídicamente hablando, el cual propicie que los proyectos de investigación de fenómenos sociales que afectan a Popayán, sean realmente resueltos por los estudiantes mediante sus propuestas de emprendimiento jurídico. Estas propuestas, de manera tímida aún, se desarrollan en las aulas de clase y se quedan como ejercicios académicos; hoy, el contexto exige un compromiso no solo de los docentes, sino de los estudiantes, a fin de darle continuidad a las soluciones jurídicas emprendedoras. Lo anterior, por cuanto - según el resultado de las encuestas aplicadas- solo el $68 \%$ de los docentes conocen el término emprendimiento, pero no son conscientes de que ellos hacen emprendimiento jurídico desde sus cursos asignados. De la misma forma, los estudiantes, en un $75 \%$, no saben que están haciendo parte del emprendimiento jurídico del que trató esta investigación y, por tanto, se requiere capacitar y orientar a nuestros docentes y estudiantes frente a la metodología de un emprendimiento jurídico, a fin de que se gesten proyectos de aula en los cursos revisados que tengan como objetivo la solución de los problemas sociales y jurídicos del entorno que pueden tener una réplica local y nacional, frente a las apuestas y propuestas que son el resultante de un semestre de estudio.

Los semilleros de investigación Ius-emprender, Derechos humanos, Derecho público 2013 y Técnicas de juicio oral, son nichos de emprendimiento jurídico ubicados en la Facultad de Derecho que posibilitarían canalizar las propuestas de estudio de problemas sociales y jurídicos, así como estructurar las posibles soluciones mediante proyectos de investigación que se plantean en los diferentes cursos, y los cuales se quedan como trabajos académicos al terminar cada semestre, a fin de que se conviertan en reales soluciones jurídicas para las comunidades, y desde allí se gesten proyectos de emprendimiento jurídico que permitirán solucionar diversos problemas, y contribuirán a la cultura de paz y del emprendimiento jurídico, como solución a algunos de las coyunturas que se avizoran en un eventual panorama de aceptación de acuerdos de paz en Colombia. Así, de esta manera, la universidad aporta soluciones reales a los diversos problemas sociales que desde el interior de sus aulas de clase se estudian, y con toda su estructura administrativa y académica permitirá promover cambios sociales en el medio en el cual se ubica, al hacer una apuesta más a sus políticas de responsabilidad social.

\section{REFERENCIAS}

Centro de Desarrollo del Espíritu Empresarial-CDEE. ICESI. Espíritu empresarial. Disponible en http://www. icesi.edu.co/espiritu_empresarial.php

Constitución Política de Colombia [Const]. Julio 7 de 1991 (Colombia).

Dolly Yazmín Camacho Corredor. Hacia un modelo de emprendimiento universitario. Revista APUNTES DEL CENES XXVII(43). I semestre del 2007. Disponible en http:// dialnet.unirioja.es/servlet/articulo?codigo $=4829113$

Fundación Universitaria de Popayán (FUP). UNIDAD DE EMPRENDIMIENTO UNDEFup. Disponible en http://fup. edu.co/web_2014/emprendimiento/undefup/

Hernando J. Gómez y Daniel Mitchell. Innovación y emprendimiento en Colombia: balance, perspectivas y recomendaciones de política, 2014-2018. CUADERNOS DE Fedesarrollo 50. 2014

Juan Carlos Catumba-Arias. PAPel De LAS Ies en LA ForMACión DE Nuevos EMPRENDEDores. Corporación Universitaria Unitec. (2013). Disponible en http://ascun.org.co/media/attachments/BOLETIN_1.pdf

Ley 1014 de 2006. De fomento a la cultura del emprendimiento. Enero 27 del 2006. Do 46164.

Ley 1448 de 2011. Por la cual se dictan medidas de atención, asistencia y reparación integral a las víctimas del conflicto armado interno y se dictan otras disposiciones. Junio 10 del 2011. Do 48096.

Ministerio de Educación Nacional. La CUltura Del EMPRENDIMIENTO EN LOS ESTABLECIMIENTOS EDUCAtivos. Orientaciones generales. Disponible en https://www.mineducacion.gov.co/1759/articles-287 822_archivo_pdf.pdf

Ministerio de la Protección Social. Guía nacional y RegionAL Del Emprendimiento. Disponible en https:// www.minsalud.gov.co/trabajoEmpleo/Paginas/emprendimi ento.aspx

Misión CIEE-Centro Institucional de Emprendimiento Empresarial. UAO. Disponible en http://www.uao.edu.co/ emprendimiento/incio/objetivos/

Pontificia Universidad Javeriana Cali. OfICINA De EMPRENDIMIEnTo. Disponible en http://www.javerianacali. edu.co/conoce-como-se-gesta-el-emprendimiento-javeriano

Unidad para la Atención y Reparación Integral a las Víctimas. CaUCA: Informe Departamental DE Hechos VICTIMIZANTES A 2012. Disponible en https://rni.unidad victimas.gov.co/sites/default/files/Documentos/ Cauca.pdf 
Universidad del Cauca. Programa "Emprende". Disponible en https://emprendimientoces.wordpress.com/ catedra-de-emprendimiento/

Universidad del Valle. Programa institucional de emPRENDEDORES. Disponible en http://extension.univalle.edu.co/index.php/emprendedores

Universidad Central del Valle (ucEva). Administración de Empresas. Disponible en http://facultades.uceva. edu.co/index.php/objetivos-de-formacion-administracion

Universidad Mariana de Nariño. UNIDAD DE EMPRENDIMIENTO COLECTIVO Y ESPÍRITU CREATIVO Y EMPRENDEDOR (CECE). Disponible en http://www.umariana. edu.co/cece/
Universidad Nacional de Colombia. Boletín JURÍdico 1 Y 2. Unidad de emprendimiento e innovación. Disponible en http://www.emprendimiento.unal.edu.co/ publicaciones/boletin-juridico

Universidad Santiago de Cali. Programa Formación DE EMPResarios. Disponible en http://orientacion. universia.net.co/informacion_carreras/pregrado/formacion-de-empresarios-snies-7804-1249/universidad-santiago-de-cali-38.html 